\title{
Researches on Sex-Change in the European Oyster.
}

THE fundamental fact about the breeding of the edible oyster is that the manifestations of this function may vary individually and in gross from season to season in a given locality, and, in general, differ also in different localities roughly according to the degree of warmth of their environment.

A modern research on the breeding of this molluse should therefore include $(a)$ adequate records of the environmental conditions, of which-if the animals are living under healthy conditions-temperature variation may be postulated as one of the most important; (b) a significant amount of healthy material the age of which has been unimpeachably determined by experimental methods; and (c) experimental observations on the successive sexconditions during one or more years of a significant number of individuals which are living under conditions as nearly natural as it is possible to attain. The modern standard of research is very high, and it is impossible for any one worker to attain it on this problem without lengthy and large-scale operations.

During late years considerable attention has been again given by workers in various parts of Europe to an inquiry on the sex-conditions and sex-changes of the European oyster (O. edulis). In 1925, R. Spärck, a young Danish biologist, published a valuable paper ${ }^{1}$ on the subject, giving the results of several years' work (1919 to 1923) on oysters obtained from the Limfjord. In a useful review of the literature on this subject, Spärck clearly shows the confusion which existed even down to recent years with regard to our ideas of sex-phenomena in one of the commonest economic molluses. The difference in opinion which existed amongst well-accredited workers in the nineteenth century is well brought out by Spärck, who finds in the literature that oysters are described variously as comprising hermaphrodite, male, and female individuals (Davaine), all potentially her. maphrodite (Lacaze-Duthiers), all mainly male or female (Mobius and Hoek), that oysters are simply protandric hermaphrodites (a popular conception even in recent years); that they do not spawn until three to four years of age ; that they do spawn. at one year ; that sex-change does occur (Davaine) or does not (Lacaze-Duthiers); that there are always 100 times more males than females (Davaine); that figures given show that there is a higher porportion of females than Davaine states (Mobius and HIoek). From these details there can be no doubt that the earlier workers had found out or surmised most of the facts, but the difficulty at the present time is to sort them out and place them in their true order; hence the need for modern critical research.

The confusion in the past has been largely due to the failure of workers to produce experimental facts, and also to the failure to differentiate fact from opinion; and indeed, until more biological work is stated in the order, experiment, observations, inference, the cycles of words used in the oyster literature of the nineteenth century are likely to be repeated in the twentieth.

In Spärck's work the difficult subject of inshore temperature variation is accounted for with a daily record at 8 A.M. of the water at Oddesund, at a position not precisely stated and the daily temperaturevariation of which is not given, nor its relations to the variation on the beds whence oysters were taken for examination. Charts of the Limfjord show the

1 "Studies on the Bjology of the Oyster (Ostren eduiz) in the Limfjord, with Special Reference to the Influence of Temperature on
3 -fathom line to lie close to the shore at Oddesund itself, but about half a mile to a mile off shore in other parts. It is well known that the temperature of shallow water on such an extensive foreshore will follow that of the air closely, and in summer the mean temperature will rise to a varying degree above the mean temperature of the air (compare when plotted together, the author's Fig. 15, which is apparently mean air, and Fig. 11), unless replaced by tidal water sweeping in directly from the open sea. It might easily happen, therefore, that while the temperature at 8 A.M. at Oddesund on a given day were $14^{\circ} \mathrm{C}$, at another position a mile away and half a mile from the shore the temperature might easily at some period of the day be $16^{\circ} \mathrm{C}$. or more (compare the author's statements on pp. 41 and 21). It is not sufficient to assume that the surface readings at Oddesund at 8 A.M. in the morning will give a correct picture of the variation in temperature over the oyster beds ; the assumption is unjustifiable, but if it were justified the proof should be given. The author's treatment of temperature records from other regions is mostly unconvincing in a similar manner. The oyster biologist should indeed command a good general and practical knowledge of hydrography, and ought to make constant use of thermometric instruments on the beds, or at least to have one up his sleeve.

Those conclusions which Spärck bases on the Oddesund temperature records-for example, that there is no fixed temperature limit below which oysters will not spawn--cannot, therefore, be regarded as substantiated by arlequate observational data. His definition of the oyster as a protandric alternating hermaphrodite is, however, supported by an increasing body of evidence, and may stand the test of time. His observations on seasonal sex-condition lead him to a conclusion similar to that formerly propounded -apparently unknown to the author-by B. Helland Hansen, namely, that complete egg-development is a product of time and temperature (calories). There will no doubt be sufficient data accumulated in the near future to settle this interesting problem.

It is also stated that egg-development ceases at $10^{\circ}$ to $12^{\circ} \mathrm{C}$. ; that at (sustained summer periods of) temperature of $20^{\circ}$ to $22^{\circ} \mathrm{C}$. each individual may become female once a year ; or only every three or four years (at sustained summer periods) at $14^{\circ}$ to $16^{\circ} \mathrm{C}$.; but the two latter at least of these statements are debatably inferential and not founded on experimental or demonstrated data.

Three valuable cases of sex-change from male to female were observed experimentally, but the number of failures to observe change is not noted, nor are the sex-changes themselves critically discussed. An observation is made by Spärck, that in regions of low salinity (and relatively high temperature) in the Limfjord, oysters appear to grow much more slowly than in regions of high salinity and relatively low temperature (p. 21); one suspects that the author is arguing in a circle from size at breeding to age and age to size, but if experimental data could be obtained to verify these statements, an important addition would be made to our knowledge on shell growth. Besides interesting remarks on seasonal feeding, on greening, on enemies, and on the fluctuations in the local stock of oysters, Spärck discusses the general effect of external conditions on sex, and arrives at the conclusion that "an alteration in the surrounding conditions results in an alteration in the kind of sex."

No. 2987, VoL. 119] 